\title{
Controlled and Reversible Stepwise Growth of Linear Copper(I) Chains Enabled by Dynamic Ligand Scaffolds
}

\author{
Orestes Rivada-Wheelaghan, Sandra L. Aristizábal, Joaquín López-Serrano, \\ Robert R. Fayzullin, and Julia R. Khusnutdinova*
}

\begin{abstract}
Title ok? $\square$ Reversible stepwise chain growth in linear $\mathrm{Cu}^{I}$ assemblies can be achieved by using the dynamic, unsymmetric naphthyridinone-based ligand scaffolds $\mathbf{L 1}$ and L2. With the same ligand scaffolds, the length of the linear copper chain can be varied from two to three and four copper atoms, and the nuclearity of the complex is easily controlled by the stepwise addition of a $\mathrm{Cu}^{I}$ precursor to gradually increase the chain length, or by the reductive removal of $\mathrm{Cu}$ atoms to decrease the chain length. This represents a rare example of a stepwise controlled chain growth in extended metal atom chains (EMACs). All complexes are formed with excellent selectivity, and the mutual transformations of the complexes of different nuclearity were found to be fast and reversible. These unusual rearrangements of metal chains of different nuclearities were achieved by a stepwise "sliding" movement of the naphthyridinone bridging fragment along the metal chain.
\end{abstract}

Linear-chain multimetallic complexes remain an active area of research owing to their applications as supramolecular building blocks and their ability to undergo multiple electron transfer steps, which play an important role in catalysis and small-molecule activation. ${ }^{[1]}$ Furthermore, one-dimensional (1D) assemblies of transition-metal complexes ("molecular wires") are of high interest for molecular microelectronics applications and studying processes of electron transfer in metal chains. ${ }^{[2]}$ Multinuclear $\mathrm{Cu}$ complexes were among the first structurally characterized and studied extended metal atom chain (EMAC) compounds. ${ }^{[2 b, 3]}$ In addition, $\mathrm{Cu}^{\mathrm{I}}$ "wires" and clusters of various nuclearities have been shown to have interesting photophysical properties that render them suitable

[*] Dr. O. Rivada-Wheelaghan, S. L. Aristizábal, Prof. J. R. Khusnutdinova Coordination Chemistry and Catalysis Unit

Okinawa Institute of Science and Technology Graduate University

1919-1 Tancha, Onna-son, Okinawa, 904-0495 (Japan)

E-mail: juliak@oist.jp

Dr. J. López-Serrano

Departamento de Química Inorgánica

Instituto de Investigaciones, Químicas (IIQ), and Centro de

Innovación en Química Avanzada (ORFEO-CINQA)

Universidad de Sevilla and Consejo Superior de Investigaciones

Científicas (CSIC)

Av. Américo Vespucio 49, Isla de la Cartuja, 41092 Seville (Spain)

Dr. R. R. Fayzullin

A.E. Arbuzov Institute of Organic and Physical Chemistry

Kazan Scientific Center, Russian Academy of Sciences

Arbuzov Street, 8, Kazan, 420088 (Russian Federation)

(2) Supporting information and the ORCID identification number(s) for

(D) the author(s) of this article can be found under:

https://doi.org/10.1002/anie.201709167. for optoelectronic applications. ${ }^{[4]} \mathrm{Cu}^{\mathrm{I}}$ polynuclear species have also been utilized as precursors in the synthesis of metalrich materials in microelectronics ${ }^{[5]}$ and as tunable dopants in OLEDs. ${ }^{[6]}$ Recently, theoretical studies indicated that multicopper coordination to DNA base pairs may improve the conductivity of DNA-based nanowires. ${ }^{[7]}$

The nuclearity of such complexes has a significant effect on their properties, and therefore, fine control over the selective formation of solution-stable polynuclear metal chains of defined lengths and geometry is needed, especially in the case of labile complexes of late first-row transition metals such as $\mathrm{Cu}^{\mathrm{I}}$. $^{[8]}$

Although polymetallic $\mathrm{Cu}^{\mathrm{I}}$ clusters of different nuclearities could be formed with simple bridging ligands such as carboxylates, the geometry of these complexes has been difficult to predict and their stability has been mostly limited to the solid state. ${ }^{[8]}$

Another method that provides better control over the geometry and nuclearity of 1D multimetallic chains is the direct combination of polynucleating multidentate ligands (e.g., oligo(pyridylamide)s $\mathbf{\square}$ ok? $\mathbf{\square}$ ) with a metal precursor to yield EMAC complexes in a one-step process (see Scheme 1 for some examples). ${ }^{[2 b, 9]}$ In this case, symmetric

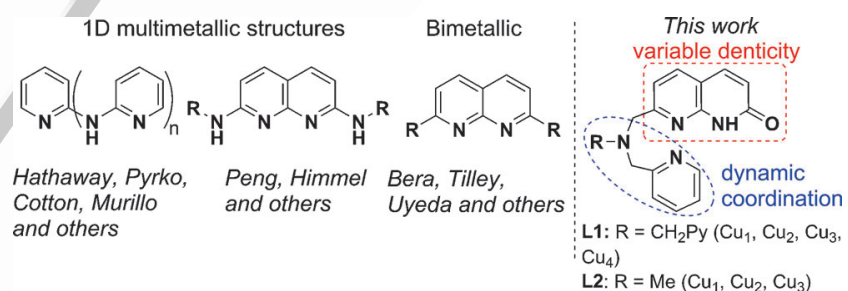

Scheme 1. Examples of polynucleating ligands for the formation of metal-chain complexes.

polynucleating ligand scaffolds that can bind a predefined number of metal atoms in a chain are typically used. However, to vary the metal chain length, new ligand scaffolds usually need to be synthesized in elaborate processes. Currently, examples of well-defined $\mathrm{Cu}^{\mathrm{I}}$ chains containing three,${ }^{[10]}$ four, ${ }^{[9 a, 11]}$ or more ${ }^{[12]} \mathrm{Cu}$ atoms are still rare.

The above methods describe bottom-up syntheses with metal precursors and ligands. To the best of our knowledge, examples of dynamic interconversions between linear chains of different nuclearities have not been reported, although examples of reversible interconversions between polynuclear complexes of different geometries are known (i.e.,

口"e.g."? - metal clusters involving non-linear metal assemblies). ${ }^{[13]}$ 
Herein, we developed the new unsymmetric dynamic ligand scaffolds $\mathbf{L 1}$ and $\mathbf{L 2}$ (Scheme 1), in which the naphthyridinone framework can be used as a versatile bridging fragment capped with bis- or monopicolyl amine units. We show that the same ligand scaffolds can be used to assemble mono-, bi-, tri-, and (with $\mathbf{L 1 )}$ tetrametallic $\mathrm{Cu}^{\mathrm{I}}$ complexes in a selective and reversible manner. Stepwise and reversible growth of the metal chain was achieved by adding the required equivalents of a $\mathrm{Cu}^{\mathrm{I}}$ precursor, which led to the selective formation of only one product, with the nuclearity changing gradually from one to four. In the reverse buildingdown process, the removal of $\mathrm{Cu}^{\mathrm{I}}$ atoms by their chemical reduction leads to a decrease in the metal chain length in a selective manner. The controlled formation of metal chains with the same ligand scaffold simplifies the synthesis and isolation of a polymetallic complex.

Moreover, reversible and selective transformations between $\mathrm{Cu}^{\mathrm{I}}$ linear chains of different nuclearity can be achieved by varying only the solvent polarity. Such reversible chain growth and interconversion processes between complexes of different nuclearity are possible owing to the versatile nature of the unsymmetric ligand scaffold, which undergoes dynamic changes in denticity and coordination mode.

The ligands $\mathbf{L 1}$ and $\mathbf{L} 2$ were obtained in yields of $70-80 \%$ by reacting 7-choro-1,8-naphthyridine-2(1H)-one with the corresponding secondary amine. ${ }^{[15]}$ Treatment of the neutral ligands $\mathbf{L 1}$ or $\mathbf{L 2}$ with 1 equiv of $\mathrm{CuCl}$ in methanol yielded the mononuclear complexes $[\mathrm{CuCl}(\mathbf{L 1})]$ and $[\mathrm{CuCl}(\mathbf{L 2})](\mathbf{1} \mathbf{a}$ and 1b, respectively) $\square$ ok? $\square$ in high yields (Scheme 2, step A). The structures of $\mathbf{1 a}$ and $\mathbf{1 b}$ were confirmed by single-crystal X-ray diffraction analysis, which also revealed hydrogen bonding between the uncoordinated $\mathrm{NH}$ group of the naphthyridinone and the chloride ligand (Figure 1). ${ }^{[1]}$ Subsequent NH group deprotonation in complexes $1 \mathbf{a}$ and 1b in the presence of $\mathrm{Cs}_{2} \mathrm{CO}_{3}$ in $\mathrm{MeCN}$ triggered the formation of the binuclear neutral complexes $[\mathrm{Cu}(\mathbf{L 1})]_{2}$ and $[\mathrm{Cu}(\mathbf{L 2})]_{2}$ (2a and $\mathbf{2} \mathbf{b}$, respectively) although $\mathbf{2 a}$ was obtained in low yield. Alternatively, selective formation of $\mathbf{2} \mathbf{a}$ in higher yield was achieved by a simple treatment of $\mathbf{L 1}$ with 1 equiv of $\left[\mathrm{Cu}(\mathrm{MeCN})_{4}\right]\left[\mathrm{BF}_{4}\right]$ in the presence of $\mathrm{Cs}_{2} \mathrm{CO}_{3}$ (Scheme 2, step B). NMR spectroscopy of $\mathbf{2 a}$ and $\mathbf{2} \mathbf{b}$ confirmed their symmetric structure in solution and the absence of the $\mathrm{NH}$ proton. Accordingly, X-ray analysis of single crystals grown from THF solutions showed that both complexes $\mathbf{2 a}$ and $\mathbf{2 b}$ contain a symmetric $\mathrm{Cu} \cdots \mathrm{Cu}$ core bridged by the nitrogen atoms of two deprotonated naphthyridinone fragments, while the oxygen atoms remain unbound (Figure 1). The $\mathrm{Cu}-\mathrm{Cu}$ bond lengths in $\mathbf{2} \mathbf{a}$ and $\mathbf{2} \mathbf{b}$ are in the range of 2.649 to $2.696 \AA$, which is somewhat shorter than the sum of their van der Waals radii $(2.80 \AA) \cdot{ }^{[\mathrm{a}]}$ Notably, the $\mathrm{Cu}-\mathrm{N}($ amine $)$ distances in $\mathbf{2} \mathbf{a}$ and $\mathbf{2} \mathbf{b}$ are greater (2.391-2.492 $\AA$ ) than typical $\mathbf{\square} \mathbf{\square}$ ok - $\mathrm{Cu}-\mathrm{N}$ bond lengths between a metal and a pyridine or naphthyridinone nitrogen atom (1.979-2.117 $\AA$ ), which could potentially contribute to the dynamic behavior of these systems (see below).

Interestingly, when crystals of $\mathbf{2} \mathbf{b}$ were grown from the less polar solvent toluene, an unsymmetric structure $\mathbf{2} \mathbf{b}^{\prime}$ was obtained (Figure 1), with shorter $\mathrm{Cu}-\mathrm{Cu}$ bonds (2.541 and

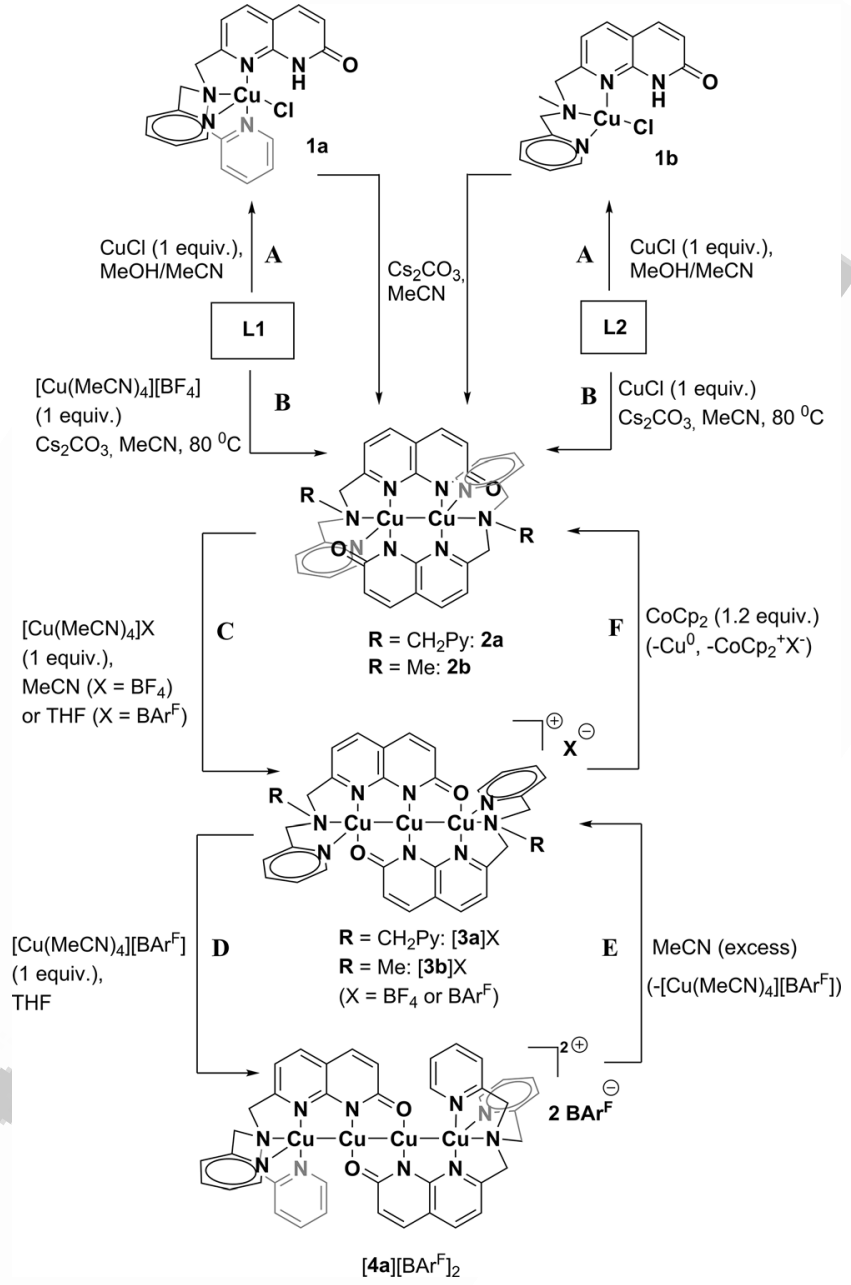

Scheme 2. Stepwise formation and interconversion of multinuclear $\mathrm{Cu}^{\prime}$ chain complexes.

$2.557 \AA$ ), and one of the copper atoms is coordinated only to two naphthyridinone $\mathrm{N}$ donors, with one of the capping picolylamine units completely unbound. In the crystal structure, there are intermolecular $\pi$-stacking interactions between the free picolyl moieties of two binuclear units (Figure 1).

The gas-phase DFT-optimized ${ }^{[16]}$ geometries of $\mathbf{2} \mathbf{b}$ and $\mathbf{2} \mathbf{b}^{\prime}$ are in good agreement with the spectroscopic and X-ray diffraction data. The calculations indicate that the symmetric structure is less stable by a mere $1.2 \mathrm{kcalmol}^{-1}$. The free energy difference is smaller in THF $\left(0.2 \mathrm{kcal} \mathrm{mol}^{-1}\right)$ than in toluene $\left(0.6 \mathrm{kcalmol}^{-1}\right)$ but the relative stability is not reversed. Regardless, both structures are almost isoenergetic, and solvent stabilization does not need to be invoked to explain the facile opening of the picolylamine capping unit.

The facile opening of the picolylamine capping unit leading to a coordinatively unsaturated copper center prompted us to study the possibility of further metal chain growth. To our satisfaction, when 1 equiv of $\left[\mathrm{Cu}(\mathrm{MeCN})_{4}\right][\mathrm{X}]$ $\left(\mathrm{X}=\mathrm{BF}_{4}\right.$ or $\mathrm{BAr}^{\mathrm{F}}$; $\mathrm{BAr}{ }^{\mathrm{F}}=$ tetrakis[3,5-bis(trifluoromethyl)phenyl]borate) was added to a solution of $\mathbf{2 a}$ or $\mathbf{2 b}$ in THF $\left(\mathrm{X}=\mathrm{BAr}^{\mathrm{F}}\right)$ or $\mathrm{MeCN}\left(\mathrm{X}=\mathrm{BF}_{4}\right)$, the new monocationic complexes $\left[\mathrm{Cu}_{3}(\mathbf{L 1})_{2}\right][\mathrm{X}]$ and $\left[\mathrm{Cu}_{3}(\mathbf{L 2})_{2}\right][\mathrm{X}](\mathbf{3} \mathbf{a} \cdot \mathrm{X}$ and $\mathbf{3 b} \cdot \mathrm{X}$, 


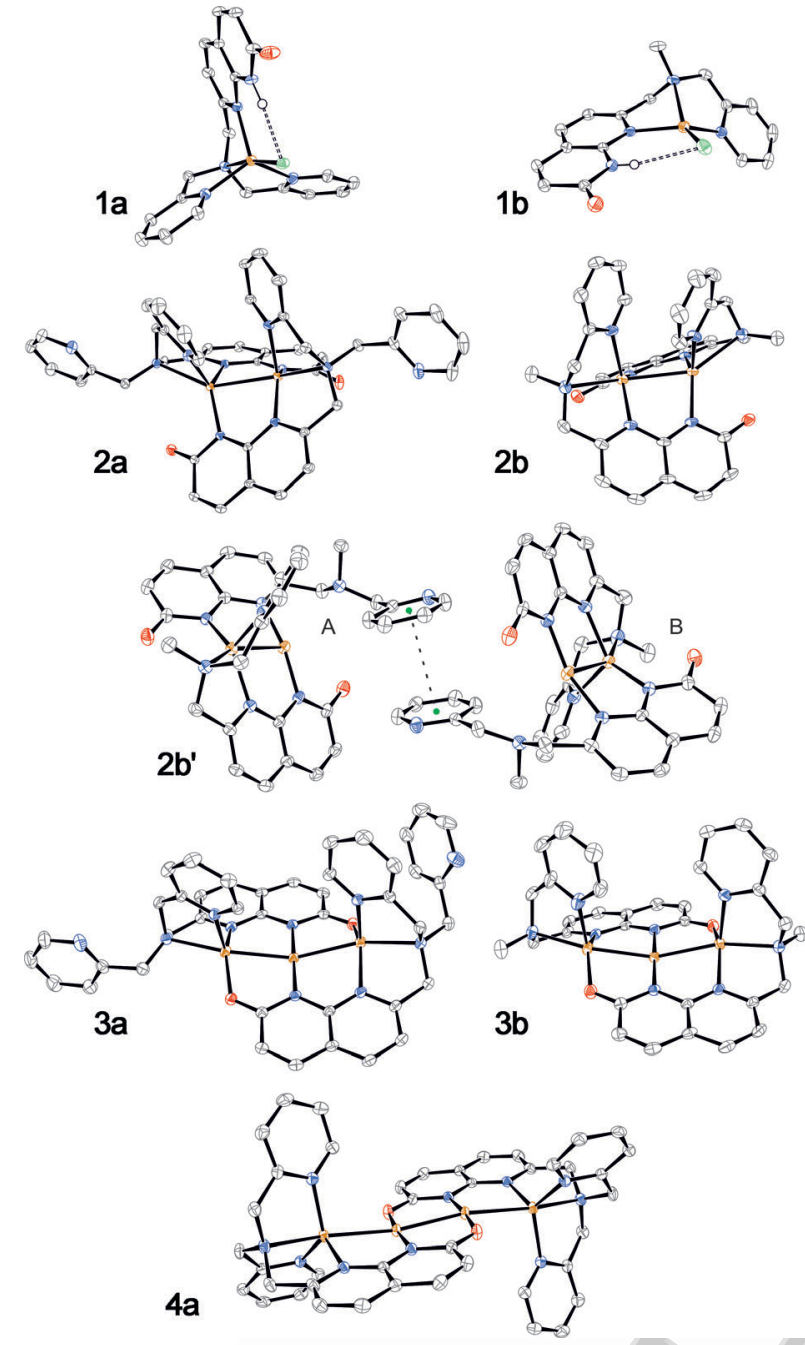

Figure 1. ORTEP plots of $\mathbf{1} \mathbf{a}, \mathbf{1} \mathbf{b}, \mathbf{2} \mathbf{a}, \mathbf{2} \mathbf{b}, \mathbf{2} \mathbf{b}^{\prime}, \mathbf{3} \mathbf{a} \cdot \mathrm{BAr} \mathrm{r}^{\mathrm{F}}, \mathbf{3} \mathbf{b} \cdot \mathrm{BAr}^{\mathrm{F}}$, and $4 \mathrm{a} \cdot \mathrm{BAr}^{\mathrm{F}}{ }_{2}$, with the thermal ellipsoids set at $50 \%$ probability. ${ }^{[14]}$ The structures of $\mathbf{3} \mathbf{a} \cdot \mathrm{BF}_{4}$ and $\mathbf{3} \mathbf{b} \cdot \mathrm{BF}_{4}$ are shown in the Supporting Information. Counterions, hydrogen atoms (except for $\mathrm{NH}$ ), and solvent molecules are omitted for clarity. For $\mathbf{2 b}$, only one of two symmetric independent molecules is depicted. In the case of $\mathbf{2} \mathbf{b}^{\prime}$, the $\pi$-stacking of the 2-picolyl arms of the independent molecule $\mathbf{A}$ and the symmetric equivalent of molecule $\mathbf{B}(1-x,-1 / 2+\gamma, 2-z)$ is shown; centroid-tocentroid distance: $3.5979(17) \AA$; plane shift: 0.999(5) $\AA$.

respectively) were obtained, which had distinct solution NMR and UV/Vis characteristics (Scheme 2, step C). The reactions occurred within seconds at $20^{\circ} \mathrm{C}$, and only the final products could be observed by ${ }^{1} \mathrm{H}$ NMR spectroscopy after $\mathrm{Cu}^{1}$ addition. The identity of the counteranion did not affect the solution NMR spectra while some broadening was observed in the NMR spectra of $\mathbf{3} \mathbf{a} \cdot \mathrm{BAr}^{\mathrm{F}}$ and $\mathbf{3 b} \cdot \mathrm{BAr}^{\mathrm{F}}$ in $\mathrm{CD}_{3} \mathrm{CN}$ solvent as compared to spectra in less coordinating $\left[\mathrm{D}_{8}\right] \mathrm{THF}$, which indicated that ligand coordination retains some dynamics. The X-ray structures of $\mathbf{3} \mathbf{a} \cdot X$ and $\mathbf{3} \mathbf{b} \cdot X$ confirmed the presence of a linear assembly of three $\mathrm{Cu}$ atoms, with $\mathrm{Cu}^{-}$ $\mathrm{Cu}$ distances in the range of 2.501-2.611 $\AA$ (Figure 1 ). Interestingly, the naphthyridinone ligand framework now acts as a trinucleating bridging fragment that is bound to the trinuclear copper core through both $\mathrm{N}$ atoms as well as one
$\mathrm{O}$ atom, demonstrating that naphthyridinone acts as a bridging ligand of variable denticity. In both $\mathbf{3 a} \cdot \mathrm{X}$ and $\mathbf{3} \mathbf{b} \cdot \mathrm{X}$, the central $\mathrm{Cu}$ atom has an almost square-planar geometry. Similar to the binuclear species, in both $\mathbf{3 a} \cdot \mathrm{X}$ and $\mathbf{3 b} \cdot \mathrm{X}$, the $\mathrm{Cu}-\mathrm{N}$ (amine) bond is longer (2.202-2.251 $\AA$ ) than typical

ok? $\mathrm{Cu}-\mathrm{N}$ bonds with pyridines and naphthyridinone $(1.882-2.152 \AA)$. The second picolyl arm in $\mathbf{3} \mathbf{a} \cdot \mathrm{X}$ remains uncoordinated, suggesting that further extension of the metal chain may still be possible.

We were delighted to see that the treatment of $\mathbf{3 a} \cdot \mathrm{BAr}^{\mathrm{F}}$ with another equivalent of $\left[\mathrm{Cu}(\mathrm{MeCN})_{4}\right]\left[\mathrm{BAr}^{\mathrm{F}}\right]$ in $\mathrm{THF}$ quantitatively yielded a new dicationic species $\left[\mathrm{Cu}_{4}(\mathbf{L 1})_{2}\right]-$ $\left[\mathrm{BAr}^{\mathrm{F}}\right]_{2}\left(\mathbf{4} \mathbf{a} \cdot \mathrm{BAr}_{2}^{\mathrm{F}}{ }_{2}\right.$; Scheme 2, step D). This tetranuclear complex displays distinct features in the solution NMR and $\mathrm{UV} / \mathrm{V}$ is spectra as compared to $\mathbf{3} \mathbf{a} \cdot \mathrm{BAr}^{\mathrm{F}}$. In particular, an absorption band was observed in the UV/Vis spectrum recorded in THF at $342 \mathrm{~nm}\left(\varepsilon=32000 \mathrm{M}^{-1} \mathrm{~cm}^{-1}\right)$ that was absent for the binuclear and trinuclear species. Single crystals were obtained from THF solution, and X-ray analysis revealed a tetranuclear linear $\mathrm{Cu}_{4}$ core with $\mathrm{Cu}-\mathrm{Cu}$ distances of 2.504 and $2.534 \AA$ (Figure 1). The two central $\mathrm{Cu}$ atoms adopt a distorted square-planar geometry. Comparison of the structures of $\mathbf{2 a}, \mathbf{3 a}$, and $\mathbf{4 a}$ reveals that as the chain length increases, the naphthyridinone fragment is "sliding" along the metal chain (see the table-of-contents graphic).

The two terminal $\mathrm{Cu}$ atoms are bound to one $\mathrm{N}$ atom of naphthyridine and are stabilized by coordination to the amine as well as to both pyridines of the bispicolylamine capping unit. The absence of such a tetranuclear complex in the case of complex $\mathbf{3} \mathbf{b}$ with monopicolyl ligand $\mathbf{L 2}$ indicates that the presence of the additional picolyl arm in $\mathbf{L 1}$ played an important role in the assembly of four copper atoms in a linear chain. All complexes $\left(\mathbf{2} \mathbf{a}, 2 \mathbf{b}, 3 \mathbf{a} \cdot \mathrm{X}, \mathbf{3} \mathbf{b} \cdot \mathrm{X}, \mathbf{4 a} \cdot \mathrm{X}_{2}\right)$ were isolated in high yields and fully characterized by NMR, UV/Vis, and FTIR spectroscopy, elemental analysis, and Xray diffraction. ${ }^{[14,15]}$ ESI-MS also confirmed the presence of the binuclear and trinuclear species in polar solvents, demonstrating that these species are viable in solution and not only in the solid state.

The selectivity of the multimetallic metal assembly can be demonstrated by solution NMR titration experiments. Stepwise addition of $\left[\mathrm{Cu}(\mathrm{MeCN})_{4}\right]\left[\mathrm{BAr}^{\mathrm{F}}\right]$ to a solution of $\mathbf{2} \mathbf{a}$ in $\left[D_{8}\right]$ THF initially resulted in the selective formation of $\mathbf{3 a} \cdot \mathrm{BAr}{ }^{\mathrm{F}}$, followed by subsequent formation of $\mathbf{4 a} \cdot \mathrm{BAr}^{\mathrm{F}}{ }_{2}$ (Figure 2).

Not only chain growth, but also chain shortening can be achieved in a selective manner. Thus switching to a different solvent also leads to reversible transformations between the tetra- and trinuclear $\mathrm{Cu}$ core. Dissolving isolated $\mathbf{4} \mathbf{a} \cdot \mathrm{BAr}^{\mathrm{F}}{ }_{2}$ in $\mathrm{CD}_{3} \mathrm{CN}$ led to the exclusive formation of $\mathbf{3 a} \cdot \mathrm{BAr}^{\mathrm{F}}$, as confirmed by NMR and UV/Vis spectroscopy, with $[\mathrm{Cu}-$ $\left.(\mathrm{MeCN})_{4}\right] \mathrm{BAr}^{\mathrm{F}}$ being a likely byproduct (Scheme 2, step E). For the reverse process, evaporation of the resulting $\mathrm{CD}_{3} \mathrm{CN}$ solution and redissolving the solid product in THF again led to the formation of $\mathbf{4 a} \cdot \mathrm{BAr}^{\mathrm{F}}$. Moreover, $\mathrm{Cu}$ atoms can be removed by chemical reduction. Thus treating $\mathbf{3 a} \cdot \mathrm{BAr}^{\mathrm{F}}$ and $\mathbf{3 b} \cdot \mathrm{BF}_{4}$ with 1.2 equiv of cobaltocene $\left(\mathrm{Cp}_{2} \mathrm{Co}\right)$ led to precipitation of metallic copper and selective formation of the corresponding binuclear complexes $\mathbf{2 a}$ and $\mathbf{2 b}$ as the only

These are not the final page numbers! 


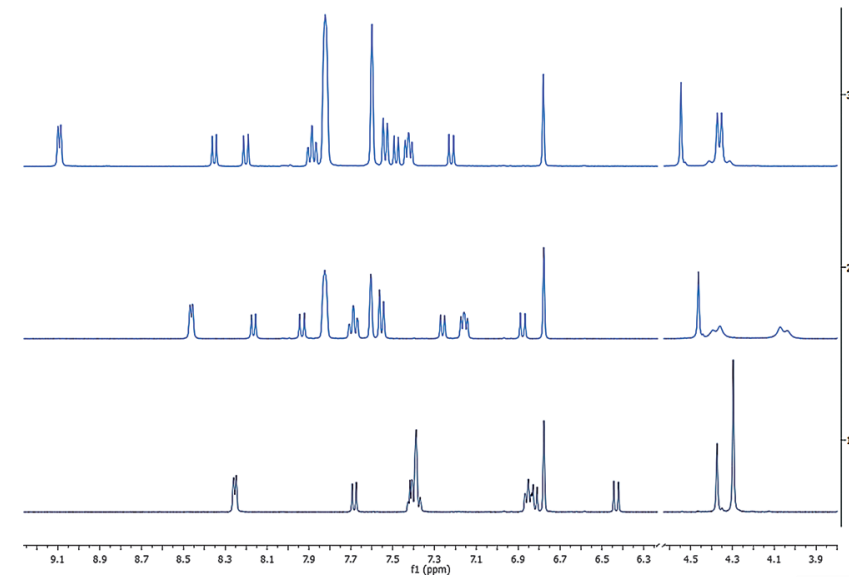

Figure 2. Stepwise formation of multinuclear $\mathrm{Cu}$ chains in $\left[\mathrm{D}_{8}\right] \mathrm{THF}$ solution at $20^{\circ} \mathrm{C}$ upon sequential addition of $\mathrm{Cu}^{\prime}$ as observed by ${ }^{1} \mathrm{H}$ NMR spectroscopy. $\square$ ok? $\mathbf{\square}$ Bottom: initial spectrum of $\mathbf{2} \mathbf{a}$; middle: spectrum after addition of 1 equiv of $\left[\mathrm{Cu}(\mathrm{MeCN})_{4}\right]\left[\mathrm{BAr}{ }^{\mathrm{F}}\right]$ to $\mathbf{2}$ a; top: spectrum after addition of a total 2 equiv of $\left[\mathrm{Cu}(\mathrm{MeCN})_{4}\right]\left[\mathrm{BAr}^{\mathrm{F}}\right]$ to 2 a.

products present in solution in $50 \%$ and $72 \%$ yield, respectively (Scheme 2, step F). To the best of our knowledge, this is the first example of a controlled stepwise formation of multimetallic linear chains varying from one to four metal atoms with high selectivity and reversibility.

In conclusion, we have developed the dynamic unsymmetric ligand scaffolds $\mathbf{L 1}$ and $\mathbf{L 2}$ for the selective and reversible formation of di-, tri-, and tetranuclear $\mathrm{Cu}$ chain complexes. This is enabled by a stepwise sliding movement of the bridging fragment along the metal chain. In contrast to previously reported examples where ligand design specific to each chain length was required, the same ligand can support a variety of chain lengths depending on the solvent polarity and stoichiometry. This is a rare example of a stepwise selective chain growth in a linear metal chain compound. Such ligand design can be useful in developing applications of multicopper complexes as flexible supramolecular building blocks and switches of variable metal chain length in a simple and selective manner. The ligand design principle described in this work can potentially be expanded to support polynuclear systems that include various kinds of metal centers by modification of the capping chelating group to include soft or hard donors of suitable geometry, or by modification of the heterocyclic framework. Moreover, the stepwise formation of polymetallic species in combination with careful adjustment of the capping fragment coordination properties may enable the selective formation of heterobimetallic complexes that selectively incorporate two kinds of metals in the terminal and central positions, an idea that we are currently investigating.

\section{Acknowledgements}

O.R.-W. is a JSPS International Research Fellow. We thank A. Villar-Briones and Dr. M. Roy for HRMS analysis and acknowledge OIST for full funding of the project. J.L.-S. acknowledges the use of computational facilities of the supercomputing center of Galicia (CESGA) and of the Centro de Servicios de Informática y Redes de Comunicaciones (CSIRC) of the Universidad de Granada (UGR).

\section{Conflict of interest}

The authors declare no conflict of interest.

Keywords: chain structures $\cdot$ copper · ligand design reversible interconversion $\cdot$ stepwise growth

[1] a) T. G. Gray, J. P. Sadighi in Molecular Metal-Metal Bonds (Ed.: S. T. Liddle), Wiley-VCH, Weinheim, 2015, pp. 397-428; b) R. C. Cammarota, L. J. Clouston, C. C. Lu, Coord. Chem. Rev. 2017, 334, 100-111; c) I. G. Powers, C. Uyeda, ACS Catal. 2017, 7, 936 -958; d) D. R. Pye, N. P. Mankad, Chem. Sci. 2017, 8 , 1705-1718; e) J. P. Krogman, C. M. Thomas, Chem. Commun. 2014, 50, 5115-5127; f) J. K. Bera, K. R. Dunbar, Angew. Chem. Int. Ed. 2002, 41, 4453-4457; Angew. Chem. 2002, 114, $4633-$ 4637.

[2] a) M. R. Mian, H. Iguchi, S. Takaishi, H. Murasugi, T. Miyamoto, H. Okamoto, H. Tanaka, S.-i. Kuroda, B. K. Breedlove, M. Yamashita, J. Am. Chem. Soc. 2017, 139, 6562-6565; b) J. F. Berry in Multiple Bonds between Metal Atoms, 3rd Ed. (Eds.: F. A. Cotton, C. A. Murillo, R. A. Walton), Springer, New York, 2005, pp. 669-706.

[3] a) J. F. Berry, F. A. Cotton, P. Lei, C. A. Murillo, Inorg. Chem. 2003, 42, 377-382; b) G. J. Pyrka, M. El-Mekki, A. A. Pinkerton, J. Chem. Soc. Chem. Commun. 1991, $84-85$; c) L. P. Wu, P. Field, T. Morrissey, C. Murphy, P. Nagle, B. Hathaway, C. Simmons, P. Thornton, J. Chem. Soc. Dalton Trans. 1990, $3835-$ 3840.

[4] a) E. Cariati, E. Lucenti, C. Botta, U. Giovanella, D. Marinotto, S. Righetto, Coord. Chem. Rev. 2016, 306, 566-614; b) V. W.-W. Yam, K. K.-W. Lo, $\mathbf{\square}$ Author names ok? $\mathbf{\square}$ Chem. Soc. Rev. 1999, 28, 323-334.

[5] A. Grodzicki, I. Lakomska, P. Piszczek, I. Szymanska, E. Szlyk, Coord. Chem. Rev. 2005, 249, 2232-2258.

[6] G. Schmid, J. H. Wemken, A. Maltenberger, C. Diez, A. Jaeger, T. Dobbertin, O. Hietsoi, C. Dubceac, M. A. Petrukhina, $A d v$. Mater. 2014, 26, 878-885.

[7] G. Li, H. Liu, X. Chen, L. Zhang, Y. Bu, J. Phys. Chem. C 2011, $115,2855-2864$.

[8] a) O. Hietsoi, A. S. Filatov, C. Dubceac, M. A. Petrukhina, Coord. Chem. Rev. 2015, 295, 125-138; b) O. Hietsoi, A. S. Filatov, C. Dubceac, M. A. Petrukhina, Dalton Trans. 2011, 40, $8598-8603$; c) O. Hietsoi, C. Dubceac, A. S. Filatov, M. A. Petrukhina, Chem. Commun. 2011, 47, 6939-6941.

[9] a) J.-F. Liu, X. Min, J.-Y. Lv, F.-X. Pan, Q.-J. Pan, Z.-M. Sun, Inorg. Chem. 2014, 53, 11068-11074; b) T. C. Davenport, T. D. Tilley, Angew. Chem. Int. Ed. 2011, 50, 12205-12208; Angew. Chem. 2011, 123, 12413 -12416; c) K. Mashima, Bull. Chem. Soc. Jpn. 2010, 83, 299-312; d) I. P.-C. Liu, W.-Z. Wang, S.-M. Peng, Chem. Commun. 2009, 4323-4331; e) Y. Takemura, T. Nakajima, T. Tanase, Dalton Trans. 2009, 10231-10243.

[10] a) P. Ai, A. A. Danopoulos, P. Braunstein, K. Y. Monakhov, Chem. Commun. 2014, 50, 103-105; b) X. He, K. RuhlandtSenge, P. P. Power, S. H. Bertz, J. Am. Chem. Soc. 1994, 116, 6963-6964; c) M. S. Tsai, S. M. Peng, J. Chem. Soc. Chem. Commun. 1991, 514-515; d) J. Beck, J. Straehle, Angew. Chem. 
Int. Ed. Engl. 1985, 24, 409-410; Angew. Chem. 1985, 97, 419420.

[11] a) C. Krämer, S. Leingang, O. Huebner, E. Kaifer, H. Wadepohl, H.-J. Himmel, Dalton Trans. 2016, 45, 16966-16983; b) B. Liu, S Pan, B. Liu, W. Chen, Inorg. Chem. 2014, 53, 10485-10497; c) N Zhao, J. Zhang, Y. Yang, H. Zhu, Y. Li, G. Fu, Inorg. Chem. 2012 51, 8710-8718; d) Y. Chen, J.-L. Li, G. S. M. Tong, W. Lu, W.-F Fu, S.-W. Lai, C.-M. Che, Chem. Sci. 2011, 2, 1509-1514; e) Z.K. Chan, Y.-Y. Wu, J.-D. Chen, C.-Y. Yeh, C.-C. Wang, Y.-F. Tsai, J.-C. Wang, Dalton Trans. 2005, 985-990; f) R. Clérac, F. A. Cotton, L. M. Daniels, J. Gu, C. A. Murillo, H.-C. Zhou, Inorg. Chem. 2000, 39, 4488-4493.

[12] M. Stollenz, J. E. Raymond, L. M. Perez, J. Wiederkehr, N. Bhuvanesh, Chem. Eur. J. 2016, 22, 2396-2405.

[13] a) A. S. Filatov, O. Hietsoi, Y. Sevryugina, N. N. Gerasimchuk, M. A. Petrukhina, Inorg. Chem. 2010, 49, 1626-1633; b) Y. Takemura, T. Nakajima, T. Tanase, M. Usuki, H. Takenaka, E. Goto, M. Mikuriya, Chem. Commun. 2009, 1664-1666; c) A
Venturelli, T. B. Rauchfuss, J. Am. Chem. Soc. 1994, 116, $4824-$ 4831.

[14] CCDC 1571963 (1a), 1571964 (1b), 1571965 (2a), 1572036 (2b), $1571966\left(\mathbf{2} \mathbf{b}^{\prime}\right), \quad 1571967\left(\mathbf{3} \mathbf{a} \cdot \mathrm{BAr}^{\mathrm{F}}\right), \quad 1571968\left(\mathbf{3} \mathbf{a} \cdot \mathrm{BF}_{4}\right)$, $1571970\left(\mathbf{3 b} \cdot \mathrm{BAr}^{\mathrm{F}}\right), 1571971\left(\mathbf{3 b} \cdot \mathrm{BF}_{4}\right)$, and $1571972\left(\mathbf{4} \mathbf{a} \cdot \mathrm{BAr}_{2}^{\mathrm{F}}\right)$ contain the supplementary crystallographic data for this paper. These data can be obtained free of charge from The Cambridge Crystallographic Data Centre.

[15] See the Supporting Information.

[16] Calculations were carried out at the DFT wB97XD/6-311 g$(d, p)+$ SDD level of theory with the Gaussian 09 software. See the Supporting Information for the full references and additional details.

Manuscript received: September 5, 2017

Accepted manuscript online: November 4, 2017

Version of record online: 


\section{Communications}

\section{Chain Structures}

O. Rivada-Wheelaghan, S. L. Aristizábal,

J. López-Serrano, R. R. Fayzullin,

J. R. Khusnutdinova*

\section{IIII-IIII}

Controlled and Reversible Stepwise

Growth of Linear Copper(I) Chains

Enabled by Dynamic Ligand Scaffolds

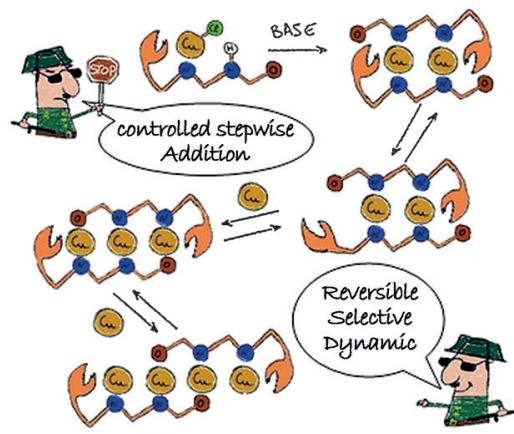

Copper chain traffic control: The stepwise growth of copper(I) linear chain complexes was achieved with dynamic ligand scaffolds. Complexes containing the same ligand and one, two, three, or four $\mathrm{Cu}^{\prime}$ atoms interconvert reversibly in a process that is controlled by the stoichiometry, solvent polarity, and redox transformations.

\section{Kettenstrukturen}

O. Rivada-Wheelaghan, S. L. Aristizábal,

J. López-Serrano, R. R. Fayzullin,

J. R. Khusnutdinova*

\section{पII-III}

Controlled and Reversible Stepwise Growth of Linear Copper(I) Chains Enabled by Dynamic Ligand Scaffolds

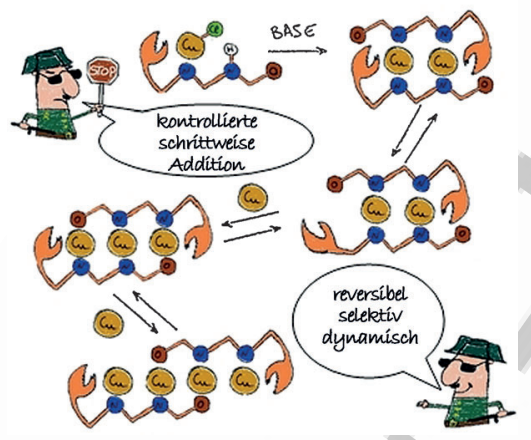

Das schrittweise Wachstum von Komplexen mit linearen Kupfer(I)-Ketten gelang mit dynamischen Ligandengerüsten. Komplexe mit dem gleichen Liganden und ein, zwei, drei oder vier Kupfer(I)-Atomen können durch Änderungen in der Stöchiometrie oder Lösungsmittelpolarität sowie durch Redoxreaktionen reversibel ineinander überführt werden.

Please check that the ORCID identifiers listed below are correct. We encourage all authors to provide an ORCID identifier for each coauthor. ORCID is a registry that provides researchers with a unique digital identifier. Some funding agencies recommend or even require the inclusion of ORCID IDs in all published articles, and authors should consult their funding agency guidelines for details. Registration is easy and free; for further information, see http://orcid.org/.

Dr. Orestes Rivada-Wheelaghan http://orcid.org/0000-0003-0381-5937

Sandra L. Aristizábal

Dr. Joaquín López-Serrano http://orcid.org/0000-0003-3999-0155

Dr. Robert R. Fayzullin http://orcid.org/0000-0002-3740-9833

Prof. Julia R. Khusnutdinova http://orcid.org/0000-0002-5911-4382 